\title{
Cascading climate effects and related ecological consequences during past centuries
}

\author{
B. Naef-Daenzer ${ }^{1}$, J. Luterbacher ${ }^{2}$, M. Nuber ${ }^{1}$, T. Rutishauser ${ }^{3}$, and W. Winkel ${ }^{4}$ \\ ${ }^{1}$ Swiss Ornithological Institute, Seerose 1, 6204 Sempach, Switzerland \\ ${ }^{2}$ Department of Geography, Climatology, Climate dynamics and Climate Change, Justus-Liebig University Giessen, \\ Senckenbergstrasse 1, 35390 Giessen, Germany \\ ${ }^{3}$ Institute of Geography and Oeschger Centre for Climate Change Research (OCCR), University of Bern, Hallerstrasse 12, \\ 3012 Bern, Switzerland \\ ${ }^{4}$ Institute of Avian Research "Vogelwarte Helgoland”, An der Vogelwarte 21, 26386 Wilhelmshaven, Germany
}

Correspondence to: B. Naef-Daenzer (beat.naef@ vogelwarte.ch)

Received: 4 April 2012 - Published in Clim. Past Discuss.: 7 June 2012

Revised: 10 September 2012 - Accepted: 11 September 2012 - Published: 10 October 2012

\begin{abstract}
The interface between climate and ecosystem structure and function is incompletely understood, partly because few ecological records start before the recent warming phase. Here, we analyse an exceptional 100-yr long record of the great tit (Parus major) population in Switzerland in relation to climate and habitat phenology. Using structural equation analysis, we demonstrate an uninterrupted cascade of significant influences of the large-scale atmospheric circulation (North-Atlantic Oscillation, NAO, and North-sea - Caspian Pattern, NCP) on habitat and breeding phenology, and further on fitness-relevant life history traits within great tit populations. We then apply the relationships of this analysis to reconstruct the circulation-driven component of fluctuations in great tit breeding phenology and productivity on the basis of new seasonal NAO and NCP indices back to $1500 \mathrm{AD}$. According to the structural equation model, the multi-decadal oscillation of the atmospheric circulation likely led to substantial variation in habitat phenology, productivity and consequently, tit population fluctuations with minima during the "Maunder Minimum" $(\sim 1650-1720)$ and the Little Ice Age Type Event I (1810-1850). The warming since 1975 was not only related with a quick shift towards earlier breeding, but also with the highest productivity since 1500 , and thus, the impact of the NAO and NCP has contributed to an unprecedented increase of the population. A verification of the structural equation model against two independent data series (1970-2000 and 1750-1900) corroborates that the retrospective model reliably depicts the major long-term NAO/NCP impact on ecosystem parameters. The
\end{abstract}

results suggest a complex cascade of climate effects beginning at a global scale and ending at the level of individual life histories. This sheds light on how large-scale climate conditions substantially affect major life history parameters within a population, and thus influence key ecosystem parameters at the scale of centuries.

\section{Introduction}

Assessing the mechanisms of long-term, large-scale ecological consequences of climate fluctuations requires quantification of causal pathways, from conditions at a continental scale down to fine-scale processes such as trophic interactions within ecosystems (e.g. Parmesan, 2006; Meehl et al., 2007; IPCC, 2007). However, such analyses are often restricted to the phenology of life history stages (e.g. Crick et al., 1997; Sokolov, 2001; Menzel et al., 2006), or to variations in the geographical distribution of species (e.g. Githaiga-Mwicigi et al., 2002; Huntley et al., 2008) as response variables. Consequently, ultimate impacts on demographic and ecological processes remain largely unclear. Research on climate effects on ecosystem structure and function contributes to explaining biogeographical patterns and factors involved in their long-term variation (Walther et al., 2002; Grosbois et al., 2006; Parmesan, 2006; Lyon et al., 2008). In particular for climate change related conservation strategies, investigations of historical records (of both climate and biodiversity) are an important basis for the 
development of long-term models (e.g. Willis et al., 2007). Recent advances in climate reconstructions into the past open a way to extending the time scale of investigations of climate - ecosystem interactions. Exploring the history of responses of ecological systems to past climate variation may therefore contribute to understand and scale the actual changes (Willis and Bhagwat, 2010; Willis and MacDonald, 2011), and to assess reaction norms and system resilience (Summers et al., 2012).

The effects of large-scale, fundamental climatic forcing (through atmospheric circulation patterns) on local habitat and the phenology of species may vary over relatively small areas (Saether et al., 2003; Both et al., 2004), and the effect size may vary substantially amongst populations of a species since both the underlying trophic interactions and the plasticity of systems may differ (Visser et al., 2002; Both et al., 2004; Gordo and Sanz, 2006, 2009; Martin, 2007; Charmantier et al., 2008). Due to the scarceness of data, climate impacts have rarely been tracked down to key parameters of population dynamics such as reproductive (Saether et al., 2003) or survival rates (Catchpole et al., 2000; Grosbois et al., 2006). Consequently, both the history and future of climate forcing on ecosystem function remain highly debated (Martin, 2007).

In birds, response to large-scale climate patterns has been reported for various species (Møller et al., 2010; Visser et al., 2002; Both et al., 2004). For tit species in particular, climate affects the phenology and reproductive traits (Sanz, 2002; Visser et al., 1998, 2002). This suggests that differential phenologies of components of the trophic web may lead to a loss of synchronization or even disruption of major trophic relationships (van Dongen, 1997; Visser et al., 1998; Przbylo et al., 2000; Adahl et al., 2006; Drever and Clark, 2007).

Here, we analyse an exceptionally long population record of great tits (Parus major Linnaeus), collected in Switzerland for the entire 20th century. Specifically, our analysis addresses three main issues: First, we aimed at tracking the effects of two large-scale atmospheric processes, the North Atlantic Oscillation (NAO, e.g. Hurrell, 1995; Wanner et al., 2001; Hurrell et al., 2003) and the North Sea - Caspian Pattern (NCP, Kutiel and Benaroch, 2002) on late winter/spring climate conditions, the effect of these envelope factors on the vegetation phenology and the tits' timing of reproduction, and ultimately, the impact on annual reproductive output. Second, we used independent phenological and reproductive data series of the habitat, the great tit and the blue tit (Cyanistes caeruleus) to validate the resulting hierarchical model quantitatively. Third, we reconstructed climate-related ecological responses back to $1500 \mathrm{AD}$ by applying the structural equation model from the 20th-century analysis to new reconstructions of monthly NAO and NCP indices. This model was verified using independent data on habitat phenology based on historical plant phenological observations for the period 1750-1900.

\section{Materials and methods}

\subsection{Great tit breeding phenology and population observations}

The great tit is a small hole-nesting passerine of deciduous and mixed forests. In Switzerland, the largest proportion of the population $(\sim 75 \%)$ occupies altitudes below $800 \mathrm{~m}$ a.s.l. (Schmid et al., 1998). The species' reproductive ecology is adapted to the quick seasonal changes in the vegetation and food resources in spring (the "caterpillar peak", NaefDaenzer and Keller, 1999; Naef-Daenzer et al., 2004; Charmantier et al., 2008; Lyon et al., 2008), and the peak in predation rates later in the season (Naef-Daenzer et al., 2001). The initiation of clutches is strongly related to ambient temperatures and the phenology of the lower levels of the trophic chain, i.e. the development of tree leaves and phyllophagous invertebrate larvae. These are the main protein supply for egg formation and nestling growth (e.g. Nager and Van Noordwijk, 1992). Thus, climatic conditions in late winter/early spring play a key role in the cascade of mechanisms influencing the annual reproductive performance (Naef-Daenzer and Keller, 1999; Charmantier et al., 2008; Lyon et al., 2008).

The nest record scheme of the Swiss Ornithological Institute recorded breeding data of great tits from 1901 to 1999 on standardised nest record cards. No great tit data were available for $22 \mathrm{yr}$ (during world wars and economic crisis), and an overwhelming part of the records was collected after 1945. The records were meticulously checked for inconsistencies in the data. We used only records with at least two visits at the nest. The date of first egg (laying date) was calculated by backdating one egg per day from the date of recording clutch size. Records with implausible data were rejected, e.g. if the time between laying date and date of reporting brood size was less than a minimum incubation period of 13 days. Where only brood size or number of fledglings was reported, no estimate of the laying date was made. Out of 7429 records, 6276 originating from 348 sites were included in the analysis, $1153(16 \%)$ records were eliminated due to one or multiple questionable entries.

The analysis includes yearly averages for laying date, clutch size, brood size and number of fledglings over all nests available per year (average $n=124$ broods, range 1-365). Since the altitudinal distribution of nest sites was constant over the study period, we used uncorrected data on breeding phenology. According to Dunn and Winkler (1999) we analysed whether years with small annual brood samples ( $<5$ broods, $N=16 \mathrm{yr}$ ) may bias the statistical results. The respective tests are given in the results section.

\subsection{Large-scale atmospheric circulation data}

The North Atlantic Oscillation Index (NAOI) is widely used as a general indicator for the strength of the westerlies over the eastern North Atlantic and western Europe and, most 
importantly, for winter and early spring climate in Europe (Hurrell, 1995; Wanner et al., 2001). For the analyses and the retrospective modelling back to 1500 , we used the series of NAO indices by Luterbacher et al. (2001, available at: http://www.cru.uea.ac.uk/cru/data/naojurg.htm). The data set is monthly resolved back to 1659 and seasonally from 1658 back to 1500 . Accordingly, we included late winter/spring NAOI on the basis of December-February indices for 1500 1658 and average January to April indices from 1659 on.

A second atmospheric teleconnection system between the North Sea and the Caspian Sea (the North Sea - Caspian Pattern NCP, Kutiel and Benaroch, 2002, available at: http: //www.cru.uea.ac.uk/cru/data/ncp/), which is similar to the EU Pattern (Barnston and Livezey, 1987) also affects the airflow over continental Europe. As with NAOI reconstructions, we reconstructed seasonal NCPI estimates for the period before 1948 on the basis of the pre-1948 station pressure series (Slonosky et al., 1999; Jones et al., 1999; Allan and Ansell, 2006) and other climate proxies back to 1500 (Luterbacher et al., 2000, 2001, 2002, 2004; Xoplaki et al., 2005). The reconstruction method and details on underlying data are given in Luterbacher et al. (2001). In its negative stage (i.e. low pressure over the North Sea) the North Sea - Caspian pattern amplifies the NAO effects, allowing westerly streams to move farther into the continent, with the effect of above normal precipitation in central Europe (Xoplaki et al., 2004). In the positive state (high pressure over the North Sea) this system counteracts the NAO effects by directing dry and cool continental air towards Central Europe.

\subsection{Local temperature, precipitation and habitat phenology}

Meteorological data were obtained from the Swiss Federal Office for Meteorology and Climatology MeteoSwiss. We included average January to April temperature and average January to April precipitation from the station Bern, Switzerland.

The date of beech (Fagus sylvatica) bud burst is an important trigger for the appearance of invertebrate food for great tits (Naef-Daenzer et al., 2004; Charmantier et al., 2008; Lyon et al., 2008). Since the spring phenologies of the most common deciduous tree species and of their invertebrate fauna are strongly correlated (for details see Fischbacher et al., 1998), historical data on beech leafing phenology are an excellent proxy for the phenology of great tit breeding habitats. The Swiss plant phenological observation network SPN (Defila, 1991; Defila and Clot, 2005) supplied data on plant phenology (www.meteoswiss.ch). We included the yearly average date of bud beech opening $(n=39-109$ observation sites/year) from the north of the Alps (19511999). Additional phenological records for 1901-1950 were extracted from the Euroclimhist database (Pfister and Dietrich, 2006). For years without records of beech phenology $(n=16)$, the bud break date was estimated from historical records of the date of cherry flowering in Liestal, Switzerland (Defila and Clot, 2005; Rutishauser and Studer, 2007; beech bud break $=40.6+0.691 \cdot$ date of cherry flowering, $R^{2}=0.77, n=49 \mathrm{yr}$ ).

\subsection{Model validation data}

We validated the final model against independent data at two levels. First, we compared structural equation model (SEM) predictions with data of great tit and blue tit laying dates and reproductive output from Braunschweig, Germany, 1970-2000 (Winkel and Hudde, 1997). We used average laying date and average number of fledglings per pair ( $N=31 \mathrm{yr}$ ). Due to the higher latitude the start of reproduction of great tits is generally later in northern Germany compared to Switzerland. To correct for this difference, we tested the residual laying date (i.e. laying date minus 31-yr average laying date) and reproductive success against predicted values as calculated from the NAOI and NCPI according to the equations in the final path model. Regression tests after Kleijnen et al. (1998) were applied to test differences between observations and predictions in respect to average or variance.

Second, we validated the retrospective model with an independent data series of the onset of spring in Switzerland for the period of 1750-1900 (Rutishauser et al., 2007; available at: http://www.ncdc.noaa.gov/paleo/phenology.html). This spring index was calculated on the basis of 23 overlapping phenological records (for methods and detailed results see Schaber and Badeck, 2002; Rutishauser et al., 2007). Unfortunately, results on the reproductive performance of the great tit cannot be verified against independent observations before 1900 due to lack of data.

A drawback in both validation exercises is that the time periods of analysis and validation overlap. Due to lack of perfectly independent data we used great tit breeding data from a distant population that was likely living under similar influence of the NAO/NCP system (Saether et al., 2003; Both et al., 2004). Thus, we cannot fully exclude collinearity with other factors, however, consider this very unlikely.

\subsection{Statistical analyses}

In summary, the data included biotic (plant phenology: beech bud burst; animal phenology: egg laying date; reproductive performance: clutch size, brood size and number of fledglings) and abiotic variables (NAOI, NCPI, station temperature and precipitation). The final data set included $77 \mathrm{yr}$ (1901-1999) in which all variables were recorded. We excluded four outliers from the analysis (all outside \pm 2.57 s.d. range, $\alpha=0.02 ; 1$ extreme in spring precipitation; 1 extreme in clutch size; 2 extremes in number of nestlings). A systematic overview of the data sets used in the analysis and models is given in Table 1.

We used structural equation modelling (SEM) with Generalized Least Squares Maximum Likelihood (GLS-ML) 
Table 1. Overview of data series used in the analysis and models.

\begin{tabular}{|c|c|c|c|c|c|c|}
\hline \multirow{2}{*}{$\begin{array}{l}\text { Parameter, } \\
\text { Application }\end{array}$} & \multicolumn{6}{|c|}{ Period } \\
\hline & 1500 & 1600 & 1700 & 1800 & 1900 & 2000 \\
\hline $\begin{array}{l}\text { Great tit phenology and productivity, 1901-1999 } \\
\text { Structural Equation Model 1901-1999 }\end{array}$ & 1 & 1 & 1 & 1 & & 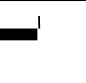 \\
\hline $\begin{array}{l}\text { Date of beech bud opening 1951-2000 } \\
\text { Structural Equation Model 1901-1999 }\end{array}$ & & & & & & = \\
\hline $\begin{array}{l}\text { Date of beech bud opening 1900-1950 } \\
\text { Structural Equation Model 1901-1999 }\end{array}$ & & & & & 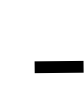 & \\
\hline $\begin{array}{l}\text { NAO index, reconstruction, } 1500-2000 \\
\text { Input to retrospective model }\end{array}$ & & & & & & \\
\hline $\begin{array}{l}\text { NCP index, reconstruction, } 1750-2000 \\
\text { Input to retrospective model }\end{array}$ & & & & & & \\
\hline $\begin{array}{l}\text { Great and blue tit demographic data, } \\
\text { Braunschweig, Germany, 1970-2000 } \\
\text { Independent validation data }\end{array}$ & & & & & & $\square$ \\
\hline $\begin{array}{l}\text { Index of spring phenology } \\
1750-1900 \\
\text { Independent validation data }\end{array}$ & & & & & - & \\
\hline
\end{tabular}

Black bars indicate time series that were used for structural equation model (SEM) analysis. Dark grey bars indicate the two time series that were used as input to the retrospective modelling. Light grey bars indicate the two time series used for model verification.

estimation for taking the hierarchical structure of the mechanisms into account (StatSoft Inc., 2006). We pre-defined a series of models assuming that all influences act from higher to lower levels of the system (i.e. atmospheric circulation $\rightarrow$ weather $\rightarrow$ vegetation/birds), but excluded any feedback upwards in this hierarchy. A set of pre-defined models was based (1) on the preliminary analysis of the effects of the NAOI and NCPI on precipitation and temperature conditions, and (2) on existing empirical and experimental evidence on the phenology of woodland habitats, and on the effects of the timing of breeding and food availability on clutch size and reproductive output (e.g. Naef-Daenzer et al., 2001; Both et al., 2004; Charmantier et al., 2008). All candidate models assumed that the atmospheric systems had no direct effect on the bird sub-system (e.g. NAOI $\rightarrow$ Clutch size), because empirical evidence for an underlying mechanism is lacking. We used the Bentler-Bonnett Non-normed index (BBnn-index, Bentler and Yuan, 1999) as measure of model fit. Like other information theoretic criteria (e.g. AIC, Anderson and Burnham, 1994), this index rewards model parsimony. We favoured the model with the highest index excluding non-significant partial relationships.

\subsection{Retrospective model 1500-2000}

The equations of the relationships in the favoured path model (as shown in Fig. 2) were implemented in the modelling package ModelMaker 2.0 (Cherwell Inc., 1995) to allow simulation of the detected long-term effect of the NAO and NCP on variation of great tit breeding parameters over the entire period for which seasonal estimates of the NAOI and NCPI are available (back to $1500 \mathrm{AD}$ ). The simulation did not include any other causal factors as input except NAOI/NCPI. Furthermore, we made no further assumptions, such as on juvenile and adult survival, because these would be entirely speculative. Thus, the simulation addresses partially the forcing of the NAO/NCP system on breeding phenology and productivity. We expressed the expected changes in the productivity relative to the average annual fecundity of 5.553 chicks per pair (1500-2000). We modelled the cumulative effects of annual variation in productivity as an index set to 100 points in year 2000. Accordingly, this relative index quantifies the partial impact of NAOI and NCPI on a theoretical population in which all other effects are kept constant. The model explicitly excludes habitat changes (such as availability of hospitable forest) and demographic mechanisms (such as density dependence and survival) that may superimpose, but not conceal, the component effect of NAOI and NCPI because no reliable assumption on the variation of these secondary dynamics over past centuries can be made. We assume that the correlations found for the 1901-1999 period did not change over the 500-yr period covered in the retrospective model. Although atmospheric teleconnections and their impact on surface climate (here late winter/spring temperature and precipitation) may vary over long periods, this likely occurs at a larger time scale than a few centuries (Hurrell and Trenberth, 2010).

The model results in respect to NAO/NCP component effects on variation in timing of breeding, reproductive performance and on population fluctuations are given as 25-yr 
moving averages (11-yr averages at ends of time series). Additionally, we applied $10 \times 2$ Fourier series polynomial regression to estimate $90 \%$ confidence bands to annual values (TableCurve 2D Ver. 4, AISN Software Inc., Lowell, Oregon, USA).

\section{Results}

\subsection{Structural equation model 1901-1999}

The correlation matrix of all variables that were included in structural equation model selection for the period 1901-1999 indicates strong relationships between the atmospheric oscillation indices and spring temperature and precipitation (Table $2, N=73 \mathrm{yr}$ ). Particularly strong were the correlation of the NAOI with spring temperatures $(r=0.57, P<0.001)$, and that of the NCPI with spring precipitation $(r=-0.75$, $P<0.001$ ). Furthermore the habitat phenology was correlated with abiotic (temperature and precipitation) and with biotic variables (laying date, reproductive performance).

Variables of bird reproduction also showed significant relationships with weather and habitat phenology (Table 2). The average annual laying date was correlated with spring temperature $(r=-0.31, P=0.008)$, spring precipitation $(r=0.26, P=0.025)$ and habitat phenology $(r=0.33, P=$ 0.004 , Fig. 1a). The average clutch size varied in relation to habitat phenology $(r=-0.39, P=0.001)$, and the average number of chicks fledged per brood was negatively related to habitat phenology $(r=-0.42, P<0.001$, Fig. $1 b)$ and temperature $(r=0.26, P=0.025)$. At the level of bivariate relationships, including the years with small brood samples increased the variance in most variables, however, caused insignificant changes in regression coefficients (Fig. 1, other correlations not shown). Furthermore, we did not find significant deviations from linear relationships in either of the pairwise correlations (not shown).

The model selection process started with interactions of the abiotic and biotic sub-systems (models 1-6, Table 3). The purpose of this first step was to clarify the relationships within the two sub-systems (first, abiotic factors: atmospheric circulation, temperature and precipitation; second, biotic factors: tit phenology and productivity). The results suggest relatively simple relationships between NAOI/NCPI and spring temperature and precipitation. Models assuming laying date as a main determinant of reproductive performance received little support (models 2-3, BBnn index 0.448-0.467). The best-supported model in the first set (model 6, Table 3) indicates that habitat phenology is the central factor for both the timing and success of tit reproduction. This model was used as the "start" model for the second set of candidate models evaluating the relationships among the abiotic and the biotic subsystems (models 7-14, Table 3).

The main link between the abiotic and the biotic subsystems in the favoured structural equation model (model
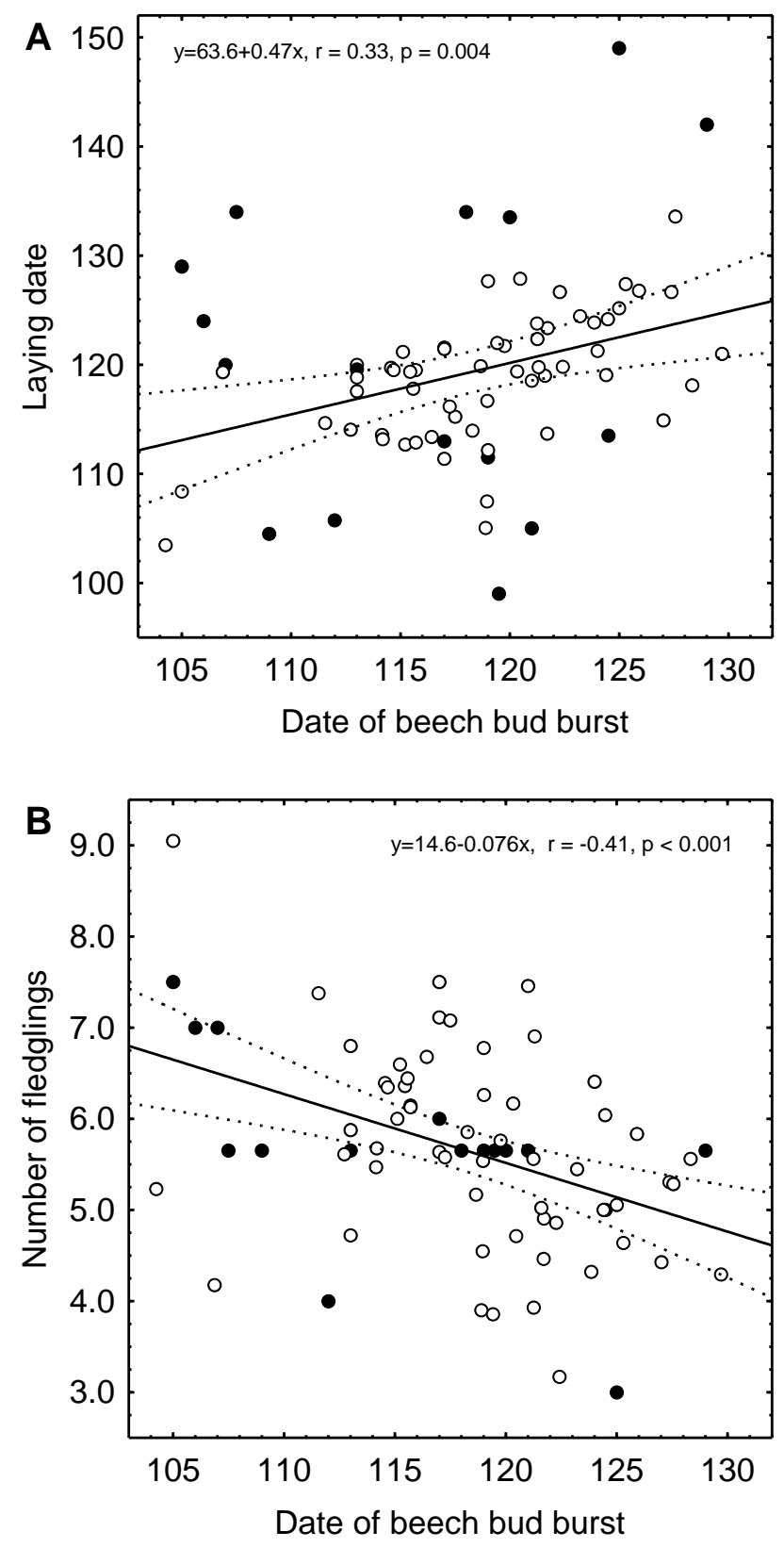

Fig. 1. (a): average annual laying date; (b) average annual number of fledglings per great tit brood in relation to the date of beech bud burst 1901-1999. Circles: years with 5 and more broods included. Dots: years with brood sample size below 5 .

14 , Table 3) was a relationship between spring temperature and habitat phenology and influences of spring precipitation on habitat phenology and laying date. All included relationships were statistically significant. Equations are given in Fig. 2, parameter estimates and statistics are given in Table 4. The favoured model suggests a chain of relationships in which the phenology of the habitat is the crucial link between the abiotic sub-system and great tit reproduction (Table 4): the NAOI explained approximately one third 
Table 2. Matrix of bivariate correlations (Pearson's $r$ ) of the variables included in the structural equation model (SEM).

\begin{tabular}{|c|c|c|c|c|c|c|c|c|c|}
\hline & & $\begin{array}{r}\text { Clutch } \\
\text { size }\end{array}$ & $\begin{array}{r}\text { Brood } \\
\text { size }\end{array}$ & $\begin{array}{r}N \text { fledg- } \\
\text { lings }\end{array}$ & $\begin{array}{r}\text { Tempe- } \\
\text { rature } \\
\text { Jan-Apr }\end{array}$ & $\begin{array}{r}\text { Precipi- } \\
\text { tation } \\
\text { Jan-Apr }\end{array}$ & $\begin{array}{r}\text { NCPI } \\
\text { Jan-Apr }\end{array}$ & $\begin{array}{r}\text { NAOI } \\
\text { Jan-Apr }\end{array}$ & $\begin{array}{r}\text { Date of } \\
\text { beech } \\
\text { bud burst }\end{array}$ \\
\hline \multirow[t]{2}{*}{ Laying date } & $r=$ & -0.19 & -0.03 & -0.12 & -0.31 & 0.26 & -0.32 & 0.05 & 0.33 \\
\hline & $P=$ & 0.102 & 0.792 & 0.321 & 0.008 & 0.025 & 0.005 & 0.653 & 0.004 \\
\hline \multirow[t]{2}{*}{ Clutch size } & & $r=$ & 0.55 & 0.24 & 0.18 & -0.13 & 0.11 & -0.05 & -0.39 \\
\hline & & $P=$ & $<0.001$ & 0.042 & 0.126 & 0.274 & 0.373 & 0.705 & 0.001 \\
\hline \multirow{2}{*}{ Brood size } & & & $r=$ & 0.45 & -0.03 & 0.08 & 0.07 & -0.10 & -0.25 \\
\hline & & & $P=$ & $<0.001$ & 0.809 & 0.517 & 0.562 & 0.417 & 0.035 \\
\hline \multirow[t]{2}{*}{$N$ fledglings } & & & & $r=$ & 0.26 & -0.02 & 0.12 & 0.15 & -0.42 \\
\hline & & & & $P=$ & 0.025 & 0.872 & 0.318 & 0.214 & $<0.001$ \\
\hline Temperature & & & & & $r=$ & -0.07 & 0.06 & 0.57 & -0.69 \\
\hline Jan-Apr & & & & & $P=$ & 0.535 & 0.613 & 0.000 & $<0.001$ \\
\hline Precipitation & & & & & & $r=$ & -0.75 & -0.06 & 0.25 \\
\hline Jan-Apr & & & & & & $P=$ & $<0.001$ & 0.612 & 0.036 \\
\hline NCPI & & & & & & & $r=$ & 0.08 & -0.24 \\
\hline Jan-Apr & & & & & & & $P=$ & 0.482 & 0.044 \\
\hline NAOI & & & & & & & & $r=$ & -0.28 \\
\hline Jan-Apr & & & & & & & & $P=$ & 0.017 \\
\hline
\end{tabular}

of the variance in late winter/spring temperature $\left(R^{2}=0.31\right.$, $P<0.001)$, whereas the NCPI accounted for approximately half of the variance in late winter/spring precipitation $\left(R^{2}=\right.$ $0.55, P<0.001)$. Second, late winter/spring temperature and precipitation influenced the date of beech bud burst. Third, the average laying date of great tits was related to habitat phenology, whereas spring temperature had no significant effect on laying dates. In years with warm late winter and spring, beech buds opened significantly earlier, and in turn the average laying date was advanced. The overall variation in average annual laying dates was large (Average Julian laying date $=119.5 \pm 8.7$ s.d., range $99-149, N=73 \mathrm{yr}$ ). Fourth, the analysis revealed a significant impact of the habitat phenology on the number of eggs laid and the number of juveniles that finally fledged. In years with early tree leafing, the reproductive output was significantly improved (number of fledglings $=14.58-0.076 \cdot$ date of beech bud opening, $\left.R^{2}=0.18, P<0.001\right)$.

The favoured model supports the hypothesis of a cascade of relationships from large-scale atmospheric circulation indices down to great tit breeding phenology and key parameters of reproductive performance. The effect size for the $\mathrm{NAO} / \mathrm{NCP}$ impact is strikingly strong. Extremes $( \pm 3$ s.d.) in NAO and NCP indices result in a differential of 1.1 fledglings per pair or $\pm 8.5 \%$ of the long-term average productivity, keeping all other effects constant. This indicates that the stages of the continental atmospheric circulations may severely shift crucial life history functions and thus, have a decisive influence of the long-term dynamics and persistence of populations.

To test the robustness of the final model against potential bias from years with small samples of great tit broods, we recalculated the SEM excluding years with less than 5 broods $(N=16)$. The changes in parameter estimates for each relationship were very small, however, the test statistics for four parameters were insignificant (results not shown). In combination with the bivariate tests for potential biases, we conclude from these tests that potential bias caused by small sample years was neglectable and that the benefit in statistical power from using the data from these years outweighed the increase in (unexplained) variance.

\subsection{Independent validation of structural equation model}

Comparing annual mean hatching dates and the mean number of fledglings in Braunschweig (1970-2000) with predictions from the favoured structural equation model, we found that neither the observed average laying date nor the number of fledglings produced differed significantly from the model prediction (Fig. 3, hatching date: $P=0.64$, number of fledglings: $P=0.95)$. However, the observed annual variance in both hatching date and number of nestlings exceeded the variance of the predictions (Fig. 3, hatching date: $P<0.001$, number of fledglings: $P<0.001)$. Hence, the structural equation model appropriately predicts the temporal 
Table 3. Model selection results for structural equation models (SEM, Generalized least squares maximum likelihood estimation). First, models 2-6 evaluate the structure within the biotic (habitat-bird) sub-system, excluding climate forcing. Second, the structure of the biotic sub-system of model 6 was kept constant to evaluate the effects of atmospheric circulation indices (NAOI/NCPI), climate (temperature/precipitation) and habitat phenology on the breeding phenology and performance. The favoured model 14 is the most parsimonious model without statistically insignificant relations. It indicates that the interface between abiotic and biotic components is via ambient temperature and precipitation, both acting on habitat phenology. Factor loadings of model 14 are given in Table 4, the path diagram and equations in Fig. 2. NAOI = North Atlantic Oscillation index, NCPI = North Sea - Caspian Pattern index, $T=$ temperature, $P R=$ precipitations, $\mathrm{PH}=$ habitat phenology (date of beech bud burst), $\mathrm{LD}=$ laying date, $\mathrm{CL}=$ clutch size, $\mathrm{BR}=$ brood size, $\mathrm{FL}=$ number of fledglings.

\begin{tabular}{|c|c|c|c|c|}
\hline \multicolumn{2}{|c|}{ Model } & \multirow{2}{*}{$\begin{array}{l}\text { Bentler-Bonett } \\
\text { Non-normed index } \\
0.0\end{array}$} & \multirow{2}{*}{$\begin{array}{l}\text { d.f. } \\
33\end{array}$} & \multirow[t]{2}{*}{ Remarks } \\
\hline 1 & Independence model & & & \\
\hline 2 & $\underset{\mathrm{NAP} \rightarrow \mathrm{PR}}{\stackrel{\mathrm{ND}}{\downarrow}} \stackrel{\mathrm{PH}}{\downarrow}$ & 0.448 & 27 & $\begin{array}{l}\text { Abiotic subsystem: NAOI, NCPI, } T \\
\text { and PR; Biotic subsystem: PH, } \\
\text { LD, CL, BR and FL. }\end{array}$ \\
\hline 3 & 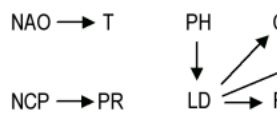 & 0.467 & 25 & \\
\hline 4 & $\begin{array}{lc}\mathrm{NAO} \rightarrow \mathrm{T} & \mathrm{PH} \\
& \downarrow \\
\mathrm{NCP} \rightarrow \mathrm{PR} & \stackrel{\mathrm{LD}}{ }\end{array}$ & 0.536 & 28 & \\
\hline 5 & $\begin{array}{l}\mathrm{NAO} \longrightarrow \mathrm{T} \\
\mathrm{NCP} \rightarrow \mathrm{PR}\end{array}$ & 0.570 & 25 & \\
\hline 6 & 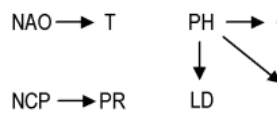 & 0.579 & 26 & $\begin{array}{l}\text { "Start" model for unrelated } \\
\text { sub-systems. }\end{array}$ \\
\hline 7 & $\underset{\mathrm{NCP} \rightarrow \mathrm{PR} \rightarrow \mathrm{LD}}{\mathrm{NAO} \rightarrow{ }^{\mathrm{T}}}$ & 0.913 & 22 & $\begin{array}{l}\text { "Full" model, several } \\
\text { relations insignificant. }\end{array}$ \\
\hline 8 & 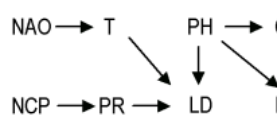 & 0.533 & 24 & $\begin{array}{l}\text { Temperature and precipitation } \\
\text { influence laying date. }\end{array}$ \\
\hline 9 & $\mathrm{NAO} \rightarrow \mathrm{T}$ & 0.578 & 24 & $\begin{array}{l}\text { Precipitation alone relates the } \\
\text { sub-systems. }\end{array}$ \\
\hline 10 & $\underset{\mathrm{NCP} \rightarrow \mathrm{NR}}{\mathrm{NAO}} \searrow_{\mathrm{L}}^{\mathrm{T}}$ & 0.734 & & $\begin{array}{l}\text { Temperature alone relates the } \\
\text { sub-systems. No effect of } \\
\text { phenology on laying date. }\end{array}$ \\
\hline 11 & $\underset{\mathrm{NCP} \rightarrow \mathrm{NR}}{\mathrm{NAO} \longrightarrow \mathrm{T}} \longrightarrow \underset{\mathrm{LD}}{\mathrm{PH}}$ & 0.853 & 24 & $\begin{array}{l}\text { Temperature relates the sub-systems. } \\
\text { Multiple effects of phenology } \\
\text { on breeding performance. }\end{array}$ \\
\hline 12 & $\underset{\mathrm{NCP} \rightarrow \mathrm{PR}}{\mathrm{NAO} \rightarrow \mathrm{LD}_{\mathrm{L}}^{\mathrm{T}}}$ & 0.878 & 23 & \\
\hline 13 & 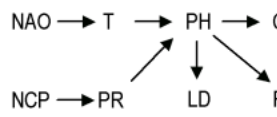 & 0.886 & 24 & $\begin{array}{l}\text { Temperature and precipitation } \\
\text { influence habitat phenology. }\end{array}$ \\
\hline 14 & 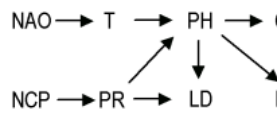 & 0.908 & 23 & $\begin{array}{l}\text { Final model. Parameter estimates } \\
\text { given in Table } 4 .\end{array}$ \\
\hline
\end{tabular}




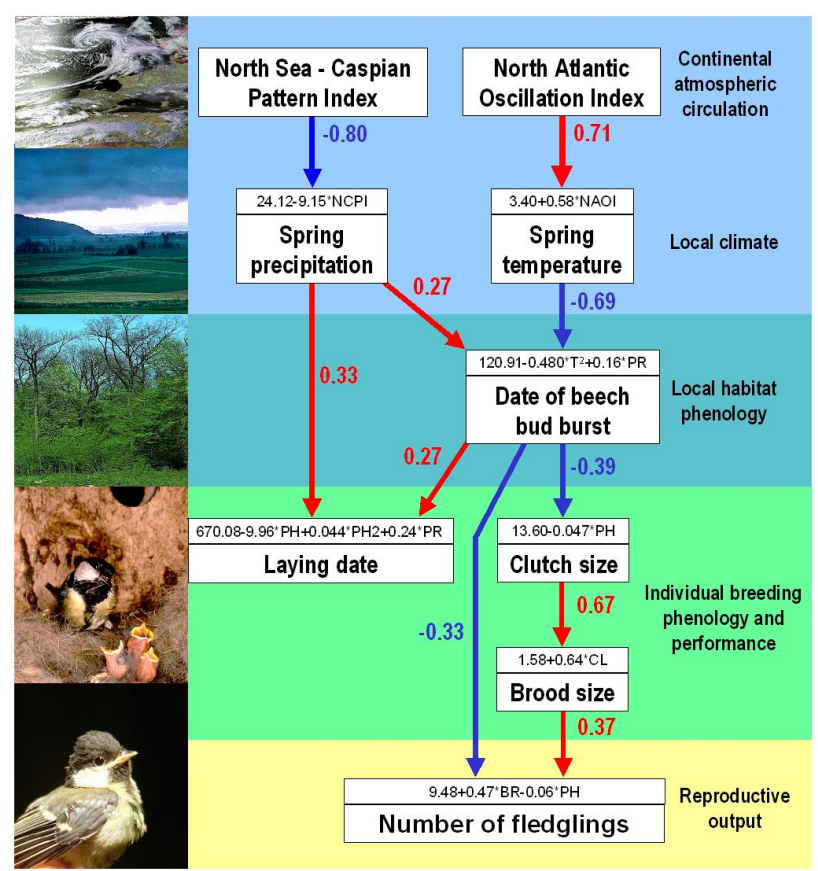

Fig. 2. Path diagram and partial equations for the chain of relationships from large-scale atmospheric circulation to great tit reproductive output. For each relationship the equation (in frames) and path coefficients (bold numbers) are given. NAOI indicates North Atlantic Oscillation index; NCPI, North Sea - Caspian Pattern index; $T$, Average annual late winter/spring temperature (January-April); PR, Average annual late winter/spring precipitation (January-April); PH, Habitat phenology, average date of beech bud burst; LD, Average annual laying date; CL, Average annual clutch size; BR, Average annual brood size. Arrow colour indicates positive (red) and negative (blue) relationships. For clarity, disturbances to the variables are not shown. Background colours indicate different stages of the cascade (see also Figs. 3-6).

variation in breeding phenology and reproductive performance. The local annual variation in these variables is larger than predicted, likely due to variables not represented in the model.

\subsection{Retrospective model 1500-2000}

The substantial impact of the NAOI/NCPI on the annual variation in fecundity may strongly contribute to long-term fluctuations of the great tit population since their stages prevail for decades (Fig. 4a, b). Thus a surplus or a deficit in population growth rates of several percent, persisting for many tit generations, may result in marked population trends. To further explore these long-term effects, we used the seasonal indices of both oscillations back to $1500 \mathrm{AD}$ to estimate the multidecadal effects on breeding phenology and fecundity. The retrospective model of the partial NAO/NCP signal in tit phenology and productivity is illustrated in Fig. 4.

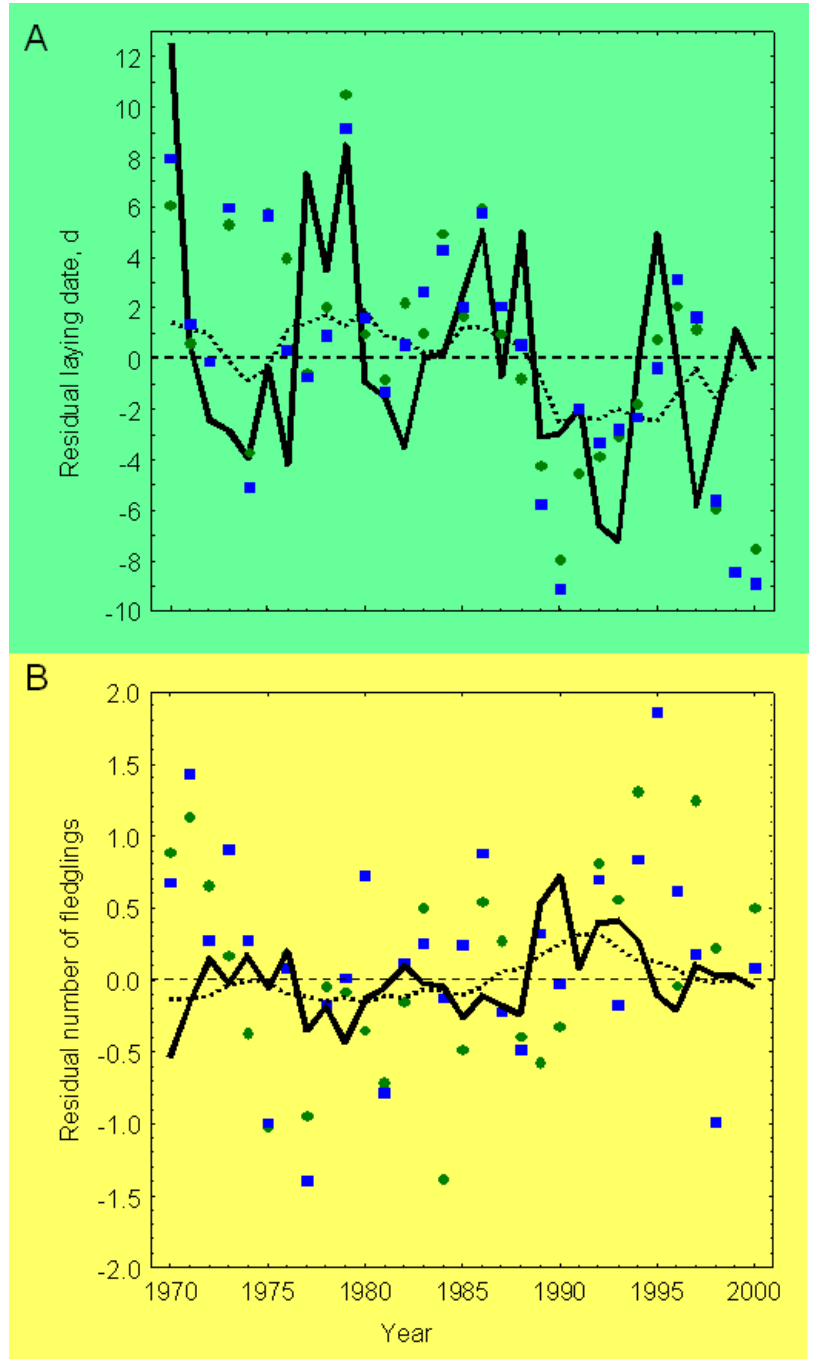

Fig. 3. Validation of structural equation model results against independent observational data. (a) Breeding phenology and (b) reproductive output in Braunschweig (Germany) 1970-2000, given as the residual from the overall average for the great tit (circles, $31 \mathrm{yr}$ ) and the blue tit (squares). Solid lines give predicted values as calculated from NAOI/NCPI data according to equations in Fig. 1. Dotted lines give 11-yr moving averages of predicted values (declining to $3-\mathrm{yr}$ at end points).

The modelling results suggest that around 1500 and 1540 1600 laying dates were relatively late, and the average productivity appeared to be slightly below average for the entire period 1500-1650. Thereafter, the model shows marked fluctuations in both laying dates and productivity (Fig. 4c, d). Three periods of early start of breeding and high productivity emerge: around 1740, 1880 and from 1975, respectively. Also, the modelled partial effect of NAOI/NCPI on a theoretical population indicates episodes of low productivity and population minima (Fig. 4e). The first minimum coincides with the Maunder Minimum (1650-1720), a second 


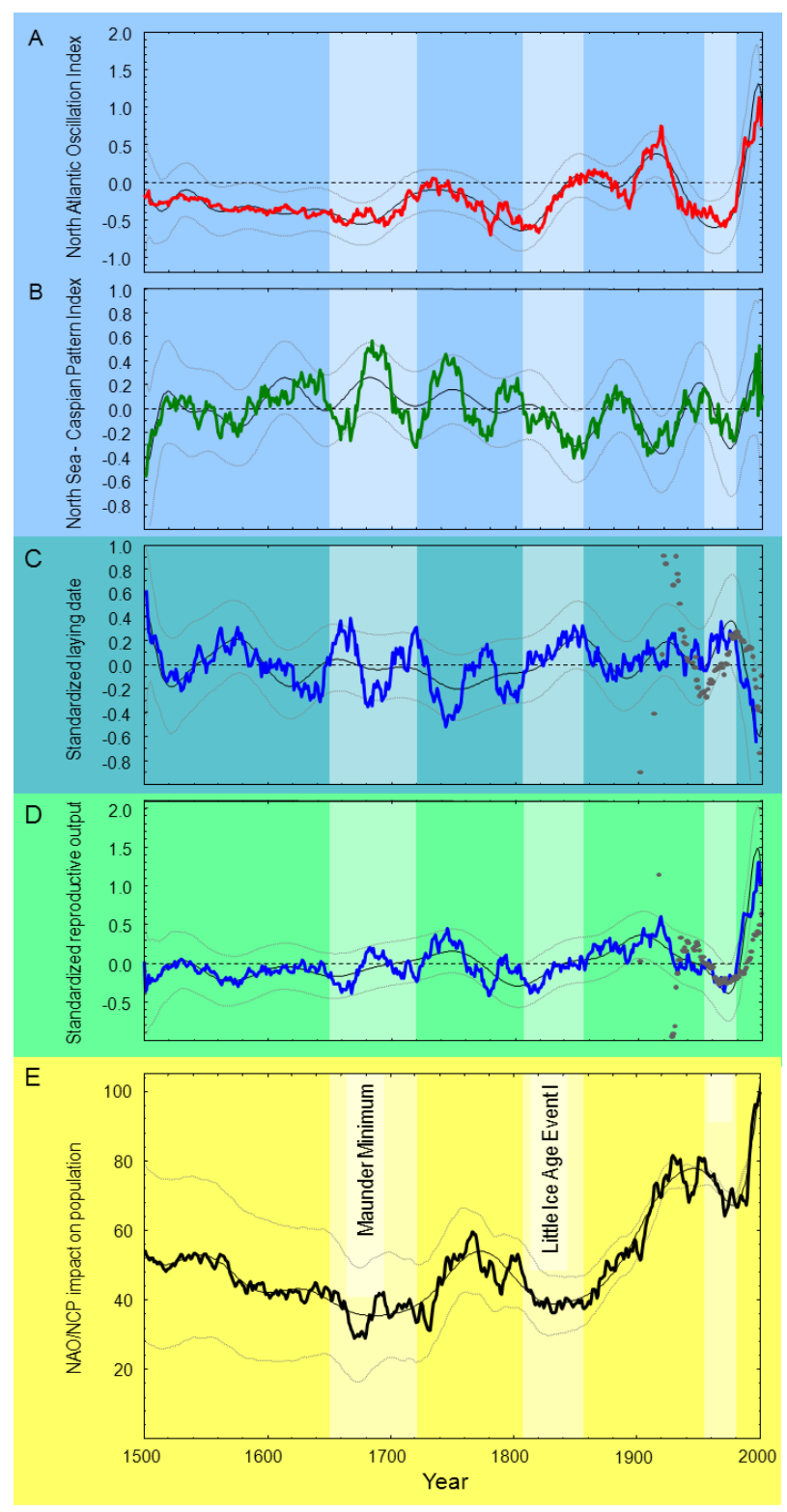

Fig. 4. The decadal fluctuation in the North Atlantic Oscillation Index NAOI and the North Sea - Caspian Pattern Index NCPI and their effect on key parameters of the great tit population in Switzerland since $1500 \mathrm{AD}$. Bold lines give 25 -yr moving averages (windows declining to $11 \mathrm{yr}$ at end points). Fine solid lines and dotted lines give the fit and $90 \%$ confidence bands to annual values by $10 \times 2$ Fourier series polynomial regression. (a) NAOI reconstruction (Luterbacher et al., 2001). (b) NCPI reconstruction (Kutiel and Benaroch, 2002, own data). Note the different scale in the y-axes in (a) and (b). (c) Standardized residual laying date as modelled from NAOI/NCPI reconstructions and the structural equation model given in Fig. 2. Grey dots give 25-yr moving averages of observed standardized residual laying dates 1901-1999 (intervals declining to 5 -yr averages at end points, raw annual observations are given before 1930) (d) standardized residual number of fledglings as modelled from NAOI/NCPI reconstructions and the structural equation model given in Fig. 2. Grey dots give 25-yr moving averages of observed standardized residual number of fledglings 1901-1999 (intervals declining to 5-yr averages at end points, raw annual observations are given before 1930). (e) Component effect of reconstructed NAOI and NCPI on the population fluctuations, expressed as an index set to 100 points in year 2000. The three minima in the population index coincide with periods in which climatic conditions in central Europe were harsh: the Maunder Minimum (1650-1720), the Little Ice Age Type Event I (1810 1850; Wanner et al., 2001), and 1950-1975. Dotted lines give \pm 2 s.e. bands of relative population index (double smoothing applied).
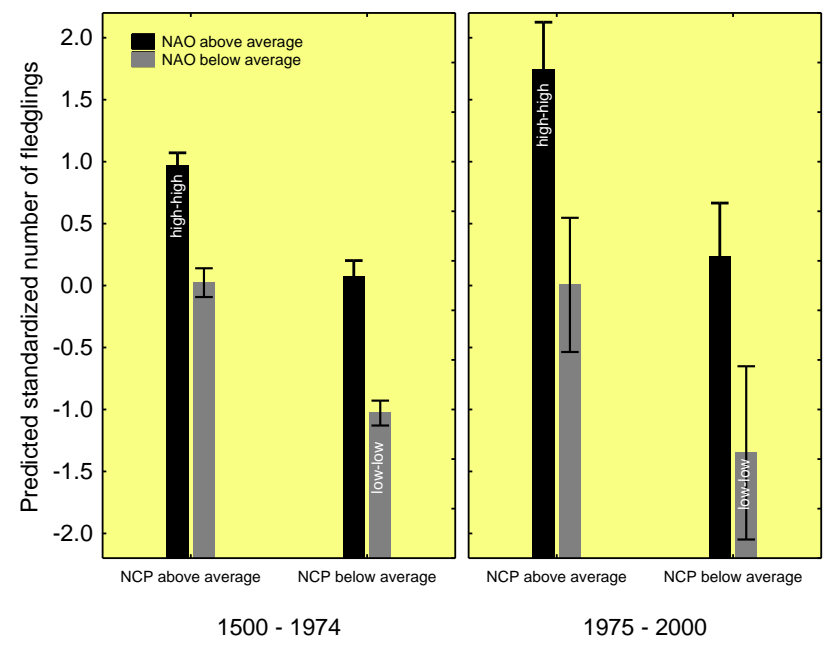

Fig. 5. Effects of high and low states of the NAOI and NCPI on the predicted annual fecundity of great tits 1500-1974 and 1975-2000, respectively (retrospective model). Coinciding high states (indices $>0$ ) of both oscillations favoured markedly increased predicted annual fecundity. When both states were low (indices $<0$ ) predicted fecundity was particularly low. After 1975, the effect was reinforced compared to the period 1500-1974. Coinciding high/high states indicate relatively warm and dry springs (see also Fig. 2 and Table 4). No significance tests were performed on predicted values. Bars give annual averages, whiskers denote $95 \%$ confidence intervals for means.

one with the Little Ice Age Type Event I (1810-1850, Wanner et al., 2001). After 1850, the modelled reproductive performance and the relative NAO/NCP population impact increase strongly and more or less steadily, except a third minimum during 1950-1975. In parallel with the strong positive trend of the NAOI from the mid-1970s to the mid-1990s, the model suggests a quick trend towards very early laying dates and a dramatic increase in reproductive output, which both exceed the range of variation over the past centuries (Fig. 4a, c and d).

At the annual scale, the model results suggest that laying dates and fecundity deviated particularly strongly from the long-term average when high or low states of the NAO and NCP coincided. Figure 5 illustrates the effects on tit fecundity of coinciding negative and positive states of the two oscillations separately for the periods from 1500-1974 and 1975-2000. This shows that the forcing of high/high and low/low constellations of the atmospheric oscillations was reinforced in the post-1975 period compared to the long-term variation. Thus, the raise in fecundity after 1975 is probably due to the over-proportional frequency of high/high states (Pearson $\chi 2=18.34$, d.f. $=4, P=0.001$ ). Coinciding high states of both oscillations signify relatively warm and dry spring weather and thus, favourable breeding conditions. 
Table 4. Parameter estimates for the favoured model 14 as in Table $3 . N=73 \mathrm{yr}$.

\begin{tabular}{lrrrr}
\hline Influence & $\begin{array}{r}\text { Parameter } \\
\text { estimate }\end{array}$ & $\begin{array}{r}\text { Standard } \\
\text { error }\end{array}$ & $t$ & $p$ \\
\hline NAOI $\rightarrow$ Temperature & 0.708 & 0.099 & 7.122 & $<0.001$ \\
NCPI $\rightarrow$ Precipitation & -0.798 & 0.055 & -14.451 & $<0.001$ \\
Temperature $\rightarrow$ Date of beech bud opening & -0.686 & 0.061 & -11.12 & $<0.001$ \\
Precipitation $\rightarrow$ Date of beech bud opening & 0.269 & 0.108 & 2.490 & 0.013 \\
Date of beech bud opening $\rightarrow$ Laying date & 0.266 & 0.118 & 2.254 & 0.024 \\
Precipitations $\rightarrow$ Laying date & 0.332 & 0.142 & 2.344 & 0.019 \\
Clutch size $\rightarrow$ Brood size & 0.673 & 0.250 & 2.551 & 0.011 \\
Brood size $\rightarrow$ Number of fledglings & 0.372 & 0.097 & 3.850 & $<0.001$ \\
Date of beech bud opening $\rightarrow$ Clutch size & -0.385 & 0.120 & -3.203 & 0.001 \\
Date of beech bud opening $\rightarrow$ Number of fledglings & -0.329 & 0.114 & -2.884 & 0.004 \\
\hline
\end{tabular}

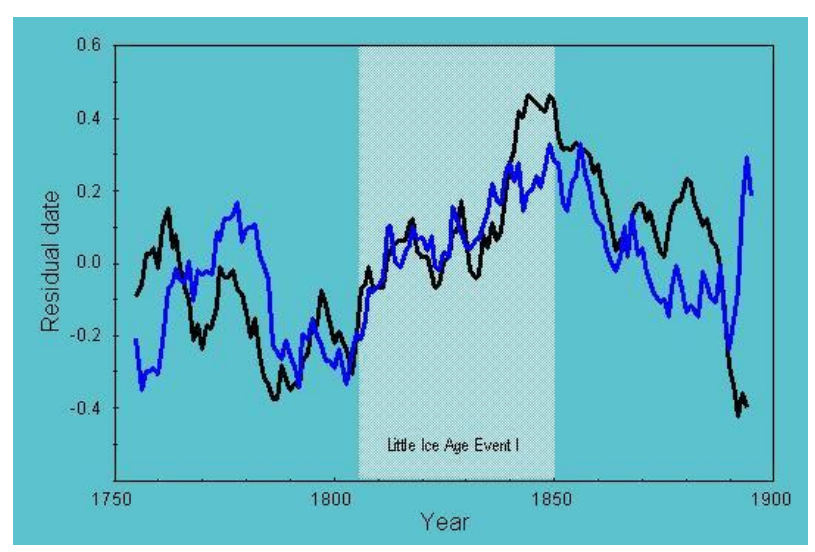

Fig. 6. Verification of the habitat phenology in the retrospective model against independent data on spring phenology 1750-1900. Blue line: modelled average laying date of great tits. Black line: index of spring phenology according to Rutishauser et al. (2007). Both indices are given as the standardized residual deviation from the long-term (1750-1900) average laying date and spring index, respectively.

\subsection{Verification of the retrospective model against independent data}

No validation data of bird phenology and productivity are available prior to 1900 . However, the estimates of habitat phenology from the retrospective model were validated against an independent data series of spring phenology 1750 1900. This period includes the Little Ice Age Event I cooling. At the interannual level, the modelling results are significantly correlated with the Rutishauser et al. (2007) spring index $\left(R^{2}=0.11, n=151 \mathrm{yr}, P<0.001\right)$, however, the relationship is weak. At a multidecadal level (25-yr moving averages), model estimations and validation data agree well $\left(R^{2}=0.32, n=141 \mathrm{yr}\right.$ (no moving averages were calculated at series edges), $P<0.001$, Fig. 6 ). This suggests that the retrospective model appropriately assessed the variation in bird breeding phenology, including warming and cooling episodes.

Qualitative evidence supports the model results of great tit production for the 19th century where no quantitative data are available. The British and European great tit populations likely decreased markedly in the first half of the 19th century, whereas after 1850 populations increased and expanded continually (Alexander and Lack, 1944; Kalela, 1950). This agrees with our reconstruction of the NAOI/NCPI-related variation of population dynamics from 1800 to present (Fig. 4d), and with the verification series of spring phenology by Rutishauser et al. (2007). We are not aware of any evidence for bird population trends before 1800 .

\section{Discussion and conclusions}

\subsection{Structural equation model 1901-1999}

The favoured structural equation model detected a substantial signal of the NAO and NCP at various levels of the ecosystem. The leafing phenology of the forest habitat was mainly determined by spring temperature and precipitation. Moreover, extremes ( \pm 3 s.d.) in the NAO and NCP indices resulted in a deviation of \pm 1.1 fledglings per pair, or $\pm 8.5 \%$ from the long-term average fecundity, keeping all other effects constant. Thus, the NAO/NCP-related variation in productivity may cause strong long-term population trends because the NAO/NCP stages prevail for many tit generations (see Fig. 4a, b). For example, a differential in annual productivity of $+2 \%$ over $25 \mathrm{yr}$ will result in a $64 \%$ population increase, an anomaly of $-2 \%$ over the same period will result in a decline by $40 \%$ (Fig. $4 \mathrm{a}, \mathrm{b}$ ). An effect of similar magnitude of the El Niño Southern Oscillation (ENSO) on the fecundity of black-throated blue warblers (Dendroica caerulescens) has been demonstrated by Sillett et al. (2000). Also, Nott et al. (2002) show impacts of the ENSO and the NAO on demographic parameters of several bird species within the late 20th century. Thus, the 
atmospheric oscillations may act similarly on many species in that they determine fundamental conditions at the scale of decades and operate at the top of cascades that include largescale weather conditions, local trophic webs and in turn, energetic conditions for reproduction. Huntley et al. (2008) calculated predictions for changing species distribution ranges on the basis of climatic envelopes for a large proportion of European breeding birds.

The data of habitat and bird phenological data available in Switzerland during the 20th century allowed structural modelling of past climate - ecosystem relationships over an exceptionally long period, including decades before the onset of the recent warming phase. Our results provide insight into the network of causal mechanisms that links atmospheric circulation patterns and bird population dynamics. They indicate that the habitat phenology plays a key role in the phenology of the entire trophic chain, and ultimately influences the final reproductive output of great tits. Furthermore, our results suggest a large plasticity of the great tit breeding system. For example, the average laying date varied by 19.5 days (10\%-90\% range). The relationship between beech bud burst and great tit start of laying was linear over this entire range, indicating no apparent limitation of the plasticity of the system within the range of variation of climate factors included in the analysis.

The structural equation model, including variables ranging from large-scale atmospheric circulation patterns to individual-scale life history processes, can neither proof the causal mechanisms linking the parts of the path model, nor can it include all steps of the trophic cascade. However, in the case of the great tit, a large record of experimental and observational evidence supports the findings at different levels of this system. Laying dates and reproductive success of the birds are particularly strongly related to the lower levels of the trophic chain (Nilsson and Källander, 2006). Experimental manipulation of ambient temperatures did not affect laying dates, but influenced the egg formation process and clutch sizes (Nager and Van Noordwijk, 1992). This supports the notion that habitat phenology and the related phenology of protein food resources (the "caterpillar peak", NaefDaenzer and Keller, 1999; Charmantier et al., 2008; Lyon et al., 2008) rather than temperature alone are the key ecological factors linking climate and great tit life histories. The validation of the structural model with independent data also corroborates the results of our analysis.

\subsection{Retrospective model 1500-2000}

Given the significant effect on average annual habitat phenology and tit reproductive performance, the NAOI and NCPI likely drive substantial long-term ecological fluctuations, since their stages prevail for long periods (Fig. 4). The retrospective model further extends the view by including multiple cycles of positive and negative stages of both atmospheric oscillations. Thus, reconstructions of past climate conditions, here monthly data for NAOI and NCPI, allowed to estimate ecological climate effects for the past half millennium. This emphasizes that the marked changes from 1975 on exceed the range of variation under past climate conditions.

In particular, the minima in tit productivity (and negative population growth rates) were correlated with periods with a late average begin of laying, and coincided with welldocumented episodes of harsh weather conditions in Europe, such as the Maunder Minimum (1650-1720) and the Little Ice Age Type Event I (1810-1850). The model indicates multiple periods during which the annual breeding performance deviated by up to 0.5 standard deviations from the long-term average (note that Fig. 3 gives 25-yr moving averages). A striking result is that the model, using seasonal NAOI and NCPI indices as the only input, also appropriately returned the shift towards an early onset of breeding and high productivity from 1975 on. For the post- 1975 period, the NAO/NCP indices predict that laying dates have advanced by 0.6 standard deviations, and reproductive rates increased by 1.2 standard deviations compared to the 500-yr average. As illustrated in Fig. 5, the reinforcing effect of the stages of the two oscillations was markedly increased for the post-1975 period. The causes of this are unclear. We conclude that over the past half millennium, the NAOI and the NCPI accounted for substantial variation in ecosystem structure and function, in particular the phenology of the habitat and important life history traits of its inhabitants.

The retrospective model partially estimates only one variance component of ecological fluctuations on the basis of newly reconstructed data for the NAO/NCP indices covering the entire $500 \mathrm{yr}$. However, detecting a signal of largescale atmospheric fluctuations, even in reproductive parameters, shows that these may affect long-term population processes. Additional factors, for example changes of the woodland habitat (whether climate related or not), density dependent variation in reproductive parameters, or variation in predation rates, likely have superimposed, but not concealed, the effect of the large-scale atmospheric circulation (see also Saether et al., 2007). We conclude that the causal chain linking large-scale atmospheric oscillations to individual life history traits, as given in the analysis part, provides an explanation for the fundamental importance of climate factors for the continent-wide spatio-temporal dynamics of the great tit (Saether et al., 2003, 2007). Combining ecological and paleoclimatological data improves insight in how global atmospheric oscillations and related climate variations determine crucial components of variance in ecosystem structure and functionality from the largest spatio-temporal scale down to the individual level. On one hand, the large variation in the phenological response of the tits (Fig. 4c) indicates high plasticity of the phenology of reproduction. This is in agreement with empirical and experimental evidence from other populations (Charmantier et al., 2008). On the other hand, the marked variation in fecundity (Fig. 4d) and demographic parameters (Fig. 4e) indicates that this plasticity cannot fully 
mitigate climate forcing on reproductive performance and thus, population persistence in various species (see also Nott et al., 2002; Both et al., 2004). The analysis of climate - ecology relationships over the past half millennium suggests that the recent changes in European woodland habitats and related trends in bird populations exceed the range of variation in the past. Future increase in anthropogenic greenhouse gas concentrations is likely to induce a positive trend in the winter NAOI (Meehl et al., 2007), and thus, amplification of the trend in great tit productivity and phenology since 1975 .

Acknowledgements. We thank Christian Pfister and Claudio Defila for providing habitat phenological data from the Euroclimhist database and the Swiss Plant Phenological Network. We are grateful to R. Fuller, M. Grosjean, J. Kaplan, Ch. Körner, T. F. Stocker, A. J. van Noordwiik and D. Winkler for helpful discussions on an earlier version of the manuscript. J. Guiot and two reviewers suggested valuable improvements of the paper. J. L. acknowledges support from the EU/FP7 project ACQWA (NO212250). J. L. also acknowledges support from the DFG Projects PRIME 1 and 2 ("Precipitation in the past millennium in Europe" and "Precipitation In past Millennia in Europe- extension back to Roman times", LU1608/1-1, AOBJ: 568460) within the Priority Programme "INTERDYNAMIK" and "Historical climatology of the Middle East based on Arabic sources back to ad 800" (LU 1608/2-1 AOBJ 575150). J. L. also acknowledges support from the Hessian Centre on Climate Change and Geology through the project "Climate Change and Extreme Weather in Hesse - Analysis of observation data and ensemble projections for the 21 st century".

Edited by: J. Guiot

\section{References}

Adahl, E., Lundberg, P., and Jonzén, N.: From climate change to population change: the need to consider annual life cycles, Glob. Change Biol., 9, 1627-1633, 2006.

Alexander, W. B. and Lack, D.: Changes in status among British breeding birds, Brit. Birds, 38, 62-69, 1944.

Allan, R. and Ansell, T.: A new globally complete monthly historical gridded mean sea level pressure dataset (HadSLP2): 18552004, J. Climate, 19, 5816-5842, 2006.

Anderson, D. R. and Burnham, K. P.: AIC model selection in overdispersed capture-recapture data, Ecology, 75, 1780-1793, 1994.

Barnston, A. G. and Livezey, R. E.: Classification, seasonality and persistence of low frequency atmospheric circulation patterns, Mon. Weather Rev., 115, 1825-1850, 1987.

Bentler, P. M. and Yuan, K.-H.: Structural Equation Modelling with Small Samples: Test Statistics, Multivar. Behav. Res., 34, 181197, 1999.

Both, C., Artemyev, A. V., Blaauw, B., Cowie, R. J., Dekhuijzen, A. J., Eeva, T., Enemar, A., Gustafsson, L., Ivankina, E. V., Järvinen, A., Metcalfe, N. B., Nyholm, N. E. I., Potti, J., Ravussin, P.-A., Sanz, J. J., Silverin, B., Slater, F. M., Sokolov, L. V., Török, J., Winkel, W., Wright, J., Zang, H., and Visser, M. E.: Large-scale geographical variation confirms that climate change causes birds to lay earlier, P. Roy. Soc. B, 271, 1657-1662, 2004.

Catchpole, E. A., Morgan, B. J. T, and Coulson, T. N.: Factors influencing soay sheep survival, Appl. Statist., 49, 453-472, 2000.

Charmantier, A., McCleery, R. H., Cole, L. R., Perrins, C., Kruuk, L. E. B., and Sheldon, B. C.: Adaptive phenotypic plasticity in response to climate change in a wild bird population, Science, 320, 800-803, 2008.

Cherwell Inc.: SB ModelMaker Ver. 2.0. Cherwell Scientific Publishing Ltd, Oxford, 1995.

Crick, H. Q. P., Dudley, C., Glue, D. E., and Thomson, D. L.: UK birds are laying eggs earlier, Nature, 388, 526-526, 1997.

Defila, C.: Pflanzenphänologie der Schweiz, Veröff. Schweiz. Meteorol. Ans., 50, 235 pp., 1991.

Defila, C. and Clot, B.: Phytophenological trends in the Swiss Alps, 1951-2002, Meteorol. Z., 14, 191-196 2005.

Drever, M. C. and Clark, R. G.: Spring temperature, clutch initiation date and duck nest success: a test of the mismatch hypothesis, Ecology, 76, 139-148, 2007.

Dunn, P. O. and Winkler, D. W.: Climate change has affected the breeding date of tree swallows throughout North America, P. Roy. Soc. B, 266, 24887-2490, 1999.

Fischbacher, M., Naef-Daenzer, B., and Naef-Daenzer, L.: Estimating caterpillar density on trees by collection of frass droppings, Ardea, 86, 121-129, 1998.

Githaiga-Mwicigi, J. M. W., Fairbanks, D. H. K., and Midgley, G.: Hierarchical processes define spatial pattern of avian assemblages restricted and endemic to the arid Karoo, South Africa, J. Biogeogr., 29, 1067-1087, 2002.

Gordo, O. and Sanz, J. J.: Climate change and bird phenology: a long-term study in the Iberian Peninsula, Glob. Change Biol., 12, 1993-2004, 2006.

Gordo, O. and Sanz, J. J.: Long-term temporal changes of plant phenology in the western Mediterranean, Glob. Change Biol., 15, 1930-1948, 2009.

Grosbois, V., Henry, P. Y., Blondel, J., Perret, P., Lebreton, J.D., Thomas, D. W., and Lambrechts, M.: Climate impacts on Mediterranean blue tit survival: an investigation across seasons and spatial scales, Glob. Change Biol., 12, 2235-2249, 2006.

Huntley, B., Green, R. E., Collingham, Y., and Willis, S. G.: A climatic Atlas of European breeding birds, Lynx Editions, Bellaterra, 2008.

Hurrell, J. W.: Decadal trends in the North Atlantic Oscillation and relationships to regional temperature and precipitation, Science, 269, 676-679, 1995.

Hurrell, J. W. and Trenberth, K. E.: Climate change, in: Effects of climate change on birds, edited by: Møller, A. P., Fiedler, W., and Berthold, P., Oxford University Press, 2010.

Hurrell, J. W., Kushnir, Y., Ottersen, G., and Visbeck, M.: The North Atlantic Oscillation. Climatic Significance and Environmental Impact, Am. Geophys. Union, Washington DC, 2003.

IPCC: Summary for Policymakers. In: Working Group II Contribution to the Intergovernmental Panel on Climate Change Fourth Assessment Report, Climate Change: Climate Change Impacts, Adaptation and Vulnerability, Cambridge University Press, 2007.

Jones, P. D., Davies, T. D., Lister, D. H., Slonosky, V., Jónsson, T., Bärring, L., Jönsson, P., Maheras, P., Kolyva-Machera, F., Barriendos, M., Martin-Vide, J., Rodriguez, R., Alcoforado, M. J., Wanner, H., Pfister, C., Luterbacher, J., Rickli, R., Schuepbach, 
E., Kaas, E., Schmith, T., Jacobeit, J., and Beck, C.: Monthly mean pressure reconstruction for Europe 1780-1995, Int. J. Climatol., 19, 347-364, 1999.

Kalela, O.: Zur säkularen Rhythmik der Arealveränderungen europäischer Vögel und Säugetiere, Orn. Fenn., 27, 1-30, 1950.

Kleijnen, J. P. C., Bettonvil, B., and Van Groenendal, W.: Validation of trace-driven simulation models: A novel regression test, Manage. Sci., 44, 812-819, 1998.

Kutiel, H. and Benaroch, Y.: North Sea Caspian Pattern (NCP) an upper level atmospheric teleconnection affecting the eastern Mediterranean: Identification and definition, Theor. Appl. Climatol., 71, 17-28, 2002.

Luterbacher, J., Rickli, R., Tinguely, C., Xoplaki, E., Schüpbach, E., Dietrich, D., Hüsler, J., Ambühl, M., Pfister, C., Beeli, P., Dietrich, U., Dannecker, A., Davies, T. D., Jones, P. D., Slonosky, V., Ogilvie, A. E. J., Maheras, P., Kolyva-Machera, F., MartinVide, J., Barriendos, M., Alcoforado, M. J., Nunez, F., Jónsson, T., Glaser, R., Jacobeit, J., Beck, C., Philipp, A., Beyer, U., Kaas, E., Schmith, T., Bärring, L., Jönsson, P., Rácz, L., and Wanner, H.: Reconstruction of monthly mean sea level pressure over Europe for the Late Maunder Minimum period (1675-1715), Int. J. Climatol., 20, 1049-1066, 2000.

Luterbacher, J., Xoplaki, E., Dietrich, D., Jones, P. D., Davies, T. D., Portis, D., Gonzalez-Rouco, J. F., von Storch, H., Gyalistras, D., Casty, C., and Wanner, H.: Extending North Atlantic Oscillation Reconstructions Back to 1500, Atmos. Sci. Lett., 2, 114-124, doi:10.1006/asle.2002.0047, 2001.

Luterbacher, J., Xoplaki, E., Dietrich, D., Rickli, R., Jacobeit, J., Beck, C., Gyalistras, D., Schmutz, C., and Wanner, H.: Reconstruction of Sea Level Pressure fields over the Eastern North Atlantic and Europe back to 1500, Clim. Dynam., 18, 545-561, 2002.

Luterbacher, J., Dietrich, D., Xoplaki, E., Grosjean, M., and Wanner, H.: European seasonal and annual temperature variability, trends, and extremes since 1500, Science, 303, 1499-1503, 2004

Lyon, B. E., Chaine, A. S., and Winkler, D. W.: A matter of timing, Science, 321, 1051-1052, 2008.

Martin, T. E.: Climate correlates of $20 \mathrm{yr}$ of trophic changes in a high-elevation riparian system, Ecology, 88, 367-380, 2007.

Menzel, A., Sparks, T. H., Estrella, N., Koch, E., Aasa, A., Ahas, R., Alm-Kübler, K., Bissolli, P., Braslavská, O., Briede, A., Chmielewski, F. M., Crepinsek, Z., Curnel, Y., Dahl, Å., Defila, C., Donnelly, A., Filella, Y., Jatczak, K., Måge, F., Mestre, A., Nordli, Ø., Peñuelas, J., Pirinen, P., Remišová, V., Scheifinger, H., Striz, M., Susnik, A., van Vliet, A. J. H., Wielgolaski, F. E., Zach, S., and Zust, A.: European phenological response to climate change matches the warming pattern, Glob. Change Biol., 2, 1969-1976, 2006.

Meehl, G. A., Stocker, T. F., Collins, W. D., Friedlingstein, P., Gaye, A. T., Gregory, J. M., Kitoh, A., Knutti, R., Murphy, J. M., Noda, A., Raper, S. C. B., Watterson, I. G., Weaver A. J., and Zhao, Z.-C.: Global Climate Projections, in: Climate Change 2007: The Physical Science Basis, Contribution of Working Group I to the Fourth Assessment Report of the Intergovernmental Panel on Climate Change, edited by: Solomon, S., Qin, D., Manning, M., Chen, Z., Marquis, M., Averyt, K. B., Tignor, M., and Miller, H. L., Cambridge University Press, Cambridge, United Kingdom and New York, NY, USA, 2007.
Møller, A. P., Fiedler, W., and Berthold, P. (Eds.): Effects of climate change on birds, Oxford University Press, 2010.

Naef-Daenzer, B. and Keller, L. F.: The foraging performance of great and blue tits (Parus major and P. caeruleus) in relation to caterpillar development, and its consequences for nestling growth and fledging weight, J. Anim. Ecol., 68, 708-718, 1999.

Naef-Daenzer, B., Widmer, F., and Nuber, M.: Differential postfledging survival of great and coal tits in relation to their condition and fledging date, J. Anim. Ecol., 70, 730-738, 2001.

Naef-Daenzer, L., Nager, R. G., Keller, L. F., and Naef-Daenzer, B.: Are hatching delays a cost or a benefit for great tit Parus major parents?, Ardea, 92, 229-238, 2004.

Nager, R. G. and Van Noordwijk, A. J.: Energetic limitations in the egg laying period of the great tit, P. Roy. Soc. Lond. B, 249, 259263, 1992.

Nilsson, J. A. and Källander, H.: Leafing phenology and timing of egg laying in great tits (Parus major) and blue tits (Parus caeruleus), J. Avian Biol., 37, 357-363, 2006.

Nott, M. P., Desante, D. F., Siegel, R. B., and Pyle, P.: Influences of the El Niño Southern oscillation and the North Atlantic oscillation on avian productivity in forests of the pacific northwest of North America, Global Ecol. Biogeogr., 11, 333-342, 2002.

Parmesan, C.: Ecological and evolutionary responses to recent climate change, Annu. Rev. Ecol. Evol. S., 37, 637-669, 2006.

Pfister, C. and Dietrich, U. (Eds.): Euro-Climhist: A database on past weather and climate in Europe and its human dimension, University of Bern, available at: www.euroclimhist.ch (last access: 9 October 2012), 2006.

Przybylo, R., Sheldon, B. C., and Merilä, J.: Climatic effects on breeding and morphology: evidence for phenotypic plasticity, J. Anim. Ecol., 69, 395-403, 2000.

Rutishauser, T. and Studer, S.: Klimawandel und der Einfluss auf die Frühlingsphänologie, Schw. Z. Forstw., 158, 105-111, 2007.

Rutishauser, T., Luterbacher, J., Jeanneret, F., Pfister, C., and Wanner, H.: A phenology-based reconstruction of inter-annual changes in past spring seasons, J. Geophys. Res., 112, G04016, doi:10.1029/2006JG000382, 2007.

Saether, B. E., Engen, S., Møller, A. P., Matthysen, E., Adriaensen, F., Fiedler, W., Leivits, A., Lambrechts, M. M., Visser, M. E., Anker-Nilssen, T., Both, C., Dhondt, A. A. , McCleery, R. H., McMeeking, J., Potti, J., Røstad, O. W., and Thomson, D.: Climate variation and regional gradients in population dynamics of two hole-nesting passerines, P. R. Soc. London, 270, 2397-2404, 2003.

Saether, B. E., Engen, S., Grøtan, V., Fiedler, W., Matthysen, E., Visser, M. E., Wright, J., Møller, A. P., Adriaensen, F., van Balen, H., Balmer, D., Mainwaring, M. C., McCleery, R. H., Pampus, M., and Winkel, W.: The extended Moran effect and large-scale synchronous fluctuations in the size of great tit and blue tit populations, J. Anim. Ecol., 76, 315-325, 2007.

Sanz, J. J.: Climate change and breeding parameters of great and blue tits throughout the western Palaearctic, Glob. Change Biol., 8, 409-422, 2002.

Schaber, J. and Badeck, F.: Evaluation of methods for the combination of phenological time series and outlier detection, Tree Physiol., 22, 973-982, 2002.

Schmid, H., Luder, R., Naef-Daenzer, B., and Zbinden, N.: Atlas of Swiss breeding birds, Swiss Ornithological Institute, Sempach, 1998. 
Sillett, T. S., Holmes, R. T., and Sherry, T. W.: Impacts of a global climate cycle on population dynamics of a migratory songbird, Science, 288, 2040-2042, 2000.

Slonosky, V. C., Jones, P. D., and Davies, T. D.: Homogenization techniques for European monthly mean surface pressure series, J. Climate, 12, 2658-2672, 1999.

Sokolov, L. V.: Spring ambient temperature as an important factor controlling timing of arrival, breeding, post-fledging dispersal and breeding success of Pied Flycatchers Ficedula hypoleuca in Eastern Baltic, Avian Ecol. Behav., 5, 79-104, 2001.

StatSoft Inc.: STATISTICA, version 7.1., available at: www.statsoft. com (last access: 9 October 2012), 2006.

Summers, D. M., Bryan, B. A., Crossman, N. D., and Meyer, W. S.: Species vulnerability to climate change: impacts on spatial conservation priorities and species representation, Glob. Change Biol., 18, 2335-2348, doi:10.1111/j.1365-2486.2012.02700.x, 2012.

Van Dongen, S., Backeljau, T., Matthysen, E., and Dhondt, A.: Synchronization of hatching date with budburst of individual host trees (Quercus robur) in the winter moth and its fitness consequences, J. Anim. Ecol., 66, 113-121, 1997.

Visser, M. E., Van Noordwijk, A. J., Tinbergen, J. M., and Lessells, C. M.: Warmer springs lead to mistimed reproduction in great tits (Parus major), P. Roy. Soc. Lond. B., 265, 1867-1870, 1998.

Visser, M. E., Adriaensen, F., Van Balen, J. H., Blondel, J., Dhondt, A. A., Van Dongen, S., Du Feu, C., Ivankina, E. V., Kerimov, A. B., De Laet, J., Matthysen, E., McCleery, R., Orell, M., and Thomson, D. L.: Variable responses to large-scale climate change in European Parus populations, P. Roy. Soc. Lond. B., 270, 367372, 2002.
Walther, G. R., Post, E., Convey, P., Menzel, A., Parmesan, C., Beebee, T. J. C., Fromentin, J.-M., Hoegh-Guldberg, O., and Bairlein, F.: Ecological responses to recent climate change, Nature, 416, 389-395, 2002.

Wanner, H., Brönnimann, S., Casty, C., Gyalistras, D., Luterbacher, J., Schmutz, C., Stephenson, D. B., and Xoplaki, E.: North Atlantic Oscillation - Concepts and Studies, Surv. Geophys., 22, 321-381, 2001.

Willis, K. J. and Bhagwat, S. A.: Questions of importance to the conservation of biological diversity: answers from the past, Clim. Past, 6, 759-769, doi:10.5194/cp-6-759-2010, 2010.

Willis, K. J. and MacDonald, G. M.: Long-Term Ecological Records and Their Relevance to Climate Change Predictions for a Warmer World, Annu. Rev. Ecol. Evol. S., 42, 267-287, 2011.

Willis, K. J., Araújo, M. B., Bennett, K. D., Figueroa-Rangel, B., Froyd, C. A., and Myers, N.: How can a knowledge of the past help to conserve the future? Biodiversity conservation and the relevance of long-term ecological studies, Philos. T. Roy. Soc. B., 362, 175-186, 2007.

Winkel, W. and Hudde, H.: Long-term trends in reproductive traits of tits (Parus major, P. caeruleus) and pied flycatchers (Ficedula hypoleuca), J. Avian Biol., 28, 187-190, 1997.

Xoplaki, E., Gonzalez-Rouco, J. F., Luterbacher, J., and Wanner, H.: Wet season Mediterranean precipitation variability: influence of large-scale dynamics and trends, Clim. Dynam., 23, 63-78, 2004.

Xoplaki, E., Luterbacher, J., Paeth, H., Dietrich, D., Steiner N., Grosjean, M., and Wanner, H.: European spring and autumn temperature variability and change of extremes over the last half millennium, Geophys. Res. Lett., 32, L15713, doi:10.1029/2005GL023424, 2005. 